\title{
Activities of the Colorado Conference of Librarians of Institutions of Higher Learning
}

Mr. Ellsworth is director of libraries, University of Colorado, Boulder.

UST AS IT IS TRUE that a family with $\int$ a low income is often more aggressive about seeking methods of getting more for its money than is a family with a large income, so is it true that colleges and universities with limited budgets have to be especially alert to ideas that will enable them to use their incomes most wisely. Although the state of Colorado is not large in population (it has I, I 18,820 people and ranks thirty-third), its per capita wealth is relatively high. ${ }^{1}$ If the expenditures of all Colorado's state-supported institutions of higher learning were added together, they would amount to $\$ 3,92$ I,7 18 annually. Their combined library holdings would be 764,008 volumes. But they are not combined. The University of Colorado at Boulder has a full university curriculum except for dentistry and social work. The Colorado State College of Agriculture and $\mathrm{Me}$ chanic Arts and the Colorado School of Mines at Golden are well-rounded schools within their specialties. The three teachers colleges all offer liberal arts work as well as professional curriculums for teach-

1 Wilson, Louis R. The Geography of Reading. University of Chicago Press, 1938, p. 357. ers. The various private colleges and universities (Denver University, Colorado College, Regis College, Colorado Woman's College, and Loretta Heights) also draw the major share of their income from within the state. When all of these are considered together, it is readily seen that the citizenry of Colorado spends liberally for the higher education of its youth.

It is equally obvious that the citizenry of Colorado cannot be expected to increase appreciably the contributions they are now making to the state-supported institutions. Therefore, if the colleges are to increase the quantity and quality of their services, it follows that the best way of doing this is to seek ways of eliminating duplications of effort.

These statements explain why the librarians of the colleges in Colorado have made a conscientious effort to find out if programs of cooperation might enable the libraries to devote a larger share of their income to the purchase of book titles and less to duplicated book collections and to technical processes. Fortunately, the librarians in Colorado, stimulated by the influence of Malcolm G. Wyer, have long understood the potentialities of cooperative action. The founding of the bibliographic center in 1932 is early evidence of their attitudes. The strength and popu- 
larity of the cooperative movement among the citizenry of the state, especially in the rural areas, suggests that proposals made by the colleges will receive an enthusiastic reception from the citizens.

Programs of the Colorado Library Association have for many years included papers and discussions on various aspects of coordinated library activities, and informal lobby conversations have often turned in this direction. In 1940 the college librarians decided to start holding a series of informal meetings to explore more systematically the possibilities of centralized action. In February I94I the group drew up a list of fourteen propositions (and we were not unmindful of the fate of President Wilson's fourteen points). One of the original points has on further consideration been dropped, leaving the following:

I. Can the institutions agree upon a bookbuying program that will result in no two institutions spending large sums of money on duplicate research collections?

2. Is it possible for the institutions to cut down on the number of current periodical subscriptions that represent duplication?

3. Can the cost of cataloging and other technical processes be cut through a state or regional cooperative cataloging program?

4. How can the present practice of interlibrary loan be extended to meet instructional needs as well as the needs of individual researchers? In other words, can collections of books for courses be loaned between two colleges that offer the same courses?

5. How can the various libraries make the fullest use of microphotography and the microphotographic laboratory services available at the University of Colorado?

6. Is it possible in our extension divisions to offer a higher type of service by farming out reference questions to the libraries that specialize in the fields concerned?

7. Are the institutions willing to allocate their library gifts and exchanges to the other institutions in terms of existing specialized collections?

8. Will the libraries consider lending to one another special types of library materials, such as pictures, slides, microfilms, etc?

9. Will the libraries be willing to work cooperatively on the problem of making relations between the library and the faculties more satisfactory?

Io. Cannot the standards of library servive be raised if the librarians all take an attitude of mutual concern toward problems of standards, practices, and ethics? (For example, had this attitude been adopted, it is possible that the other librarians could have convinced the University of Colorado many years ago that its practice of hiring untrained librarians would some day prove to be expensive and unwise.)

II. Is there any possibility of coordinating the extension services of the various institutions, especially in terms of mutual use of audio-visual materials and personnel?

12. What is to be the future of the relations between each institution and the bibliographic center when the time comes for financial contributions?

13. How can the librarians in institutions involved in teacher-training programs solve the problem of offering instruction for teacher-librarians?

These thirteen propositions represent what our group proposed to study. The various activities of the bibliographic center, such as the cooperative book-buying program, are not included in this report.

Actually, the work of the last two years has centered around the first three propositions, because these are the most important ones.

\section{Problem of Curriculum Duplication}

Propositions I and 2. We soon agreed that if we were to make any progress in avoiding the building of duplicate book and periodical collections, we would have to find some means of eliminating the 
duplication of curriculums of the various state colleges, because it seemed obvious to us that book collections would have to be maintained for each subject wherever it was taught. Our problem, therefore, was to try to show the administrations and faculties of the various state colleges that if they were interested in having better library collections, they would first have to eliminate duplication in the curriculums. There is no problem in convincing anyone that duplicate libraries are inevitable when specific subjects are taught similarly in two or more places. But it is not so obvious that duplicate libraries are also inevitable when a subject is approached from two points of view. For example, geology and engineering are approached differently in the University of Colorado and the school of mines. Yet both institutions have to have essentially the same libraries in engineering and geology. The same is true of zoology and botany for the university and the state college of agriculture and mechanic arts. Since the latter is concerned with the agricultural aspect of engineering, it too has to have an engineering library that is similar in many ways to those of the university and the school of mines. Thus, in many fields, it has been necessary to build duplicate libraries in the various colleges.

\section{Library Duplication}

Our group realized that in discussing the matter we were treading on dangerous ground and that we would be accused of sticking our noses in other people's business. We knew, however, that the solution to our library problem could be approached in no other way.

We, therefore, undertook two projects which we thought would be useful in convincing faculties and administrations that library duplication was a result of duplication of curriculums.

First, we began the compilation of a list of periodicals currently received in all the libraries. (We decided also to include the privately supported college libraries in our group as well as the Denver Public Library.) This list was completed in January 1943 and has been distributed. The librarian in each institution is responsible for seeing that the proper officials and groups in each college study the list. It is too early to say what the results will be.

Second, although most of us are aware of the nature of the curriculums of the various colleges, it is not easy to find out from the college catalogs just what subjects are taught at the colleges and at what levels the subjects are taught. We therefore agreed to compile a list of the course offerings, at six instructional levels, of the various institutions. We hoped to be able to include in this list a statement of the adequacy of the book collection in each institution for each subject at each instructional level. We have not been able to do this.

\section{Comparison of Courses}

The compilation of the document has proved to be difficult and time-consuming because a specific subject may be taught in different departments and from different points of view in several institutions. For example, nutrition is taught in the home economics department and as a subject for research in the chemistry department of the University of Colorado; in the agricultural colleges, it is in the home economics department; and in the Colorado State College of Education, it is taught as a part of the home arts courses. 
A preliminary edition of the list was finished in November 194I. At this time our group sponsored a meeting in Boulder of the college presidents, graduate school deans, arts college deans, and librarians to discuss the preliminary list of course offerings, with its library implications. We planned to use this meeting as a means of acquainting the deans and presidents with the problems our group was struggling with and, if possible, to enlist their aid. We hoped also to spend some time studying the possibilities of the microphotographic process in developing our research collections.

The list of course offerings was compiled in such a way that for each subject, or division thereof, one could see what each institution was doing and at what level. Six levels were used:

I. Scattered undergraduate courses with no major or minor.

2. Basic undergraduate courses with majors or minors.

3. Scattered graduate courses with no graduate major or minor.

4. Basic graduate courses with majors or minors, or as possible thesis fields.

5. Ph.D. theses written in the field.

6. Special research work carried on but no curriculum involved.

The list was microfilmed and was to be shown to the meeting with the aid of a projector. Unfortunately, the projector broke down during the showing, thus pre-

venting a full discussion of the problem of duplication of curriculums. A fine opportunity was badly muffed. The writer, who was responsible, didn't sleep well for several nights after that!

Nevertheless, enough information was presented to make possible a discussion of the basic issue, and we were able to establish our point, which was that it would be necessary to continue duplicating li- braries as long as the curriculums of the colleges overlapped. It was also generally agreed that it would be desirable to hold combined meetings of deans and librarians to continue discussion of the problem.

\section{Microphotography}

Part of the meeting was spent discussing microphotography. Three wellknown scholars in the fields of science, social science, and the humanities commented on the advantages and disadvantages of the process as a means of building library resources in their respective fields. The processes of microfilming and microprinting were defined and illustrated along with the equipment used. The University of Colorado's program for microfilming theses was described, and it was suggested that it might be a good thing to have the theses from all the colleges microfilmed and a joint list of thesis abstracts published.

Thus, in spite of the failure of the projector, the meeting was reasonably successful.

The final edition of the list of course offerings has since been completed and turned over to the college presidents. The war has, of course, changed the picture completely and has caused radical curricular revisions. This situation has one possible advantage in that when the war is over and the colleges begin to "retool" for the postwar activities, it is possible that they can use the list of course offerings in developing new curriculums. This assumes that the colleges can agree on the principle of eliminating duplication of curriculums beyond the level of general education. No one in our group is naive enough to believe that accomplishment of this will be easy or even possible. 


\section{Centralized Technical Processes}

Proposition 3. In March 194I the conference concentrated its attention on the problem of centralized cataloging and other technical processes. In order to focus the discussion the chairman proposed that all technical processes be handled for all the state-supported institutions at the University of Colorado Library. This served to open the discussion with a vengeance. The resulting discussion brought us quickly to a realization that the problem was not a simple one and that many aspects would have to be studied. Everyone expressed willingness to agree if the program could be made practical and if it would serve to cut costs for all institutions. The problem of where the work was to be done was considered to be of minor importance. The inevitable committee was appointed, and after many months of hard work the committee submitted its first report in August 1942. This has been circulated in mimeographed form under the title "First Report of the Special Committee for Centralized Technical Processes and Book Buying." Copies can be secured from James G. Hodgson, Colorado State College of Agriculture and Mechanic Arts, Fort Collins. This was followed in October by a second report, "Planning Studies in Centralization."

The issuance of these reports has caused vigorous and honest differences of opinion in the conference as to future procedure. The first group, under the leadership of Mr. Hodgson, believes that the present situation should be used as the occasion for the launching of a thorough, long-time series of investigations of the whole process of cataloging and of other technical processes, based somewhat on the outline presented in the first report of the committee.
Mr. Hodgson has organized a steering committee of librarians which will outline, supervise, and coordinate a long series of researches on various aspects of the technical processes. The specific researches are to be done in the library schools, by bureaus of governmental research, and by such other individuals and groups as can be interested in the idea. The steering committee will suggest, coordinate, and interpret.

\section{Need for Preliminary Study}

The second group in the conference agrees that as long as the present structure of cataloging is considered fundamentally sound, needing only polishing and correcting here and there, the researches outlined by Mr. Hodgson's group are logical and necessary. This group thinks, however, that if the present structure should prove to be fundamentally unsound, it would be a waste of time to study all aspects of cataloging and centralized technical processes until the first part, "Basic Studies on the Nature of the Technical Processes," has been thoroughly investigated. Until we have better understanding of the bibliographic needs of college and university clientele, we are not yet ready to say that the present system of classification and cataloging is right or wrong. Neither can we be in a position to think out a new and logical approach to the problem until the preliminary work is done. If a melodramatic figure of speech may be used, the second group doesn't see much point in scouring the decks of a ship that is in imminent danger of being sent to the bottom by a torpedo.

Both groups agree that the first step is to study the bibliographic habits and needs of college and university clientele and, once these are defined and under- 
stood, to proceed to scrutinize the present cataloging and bibliographic practices in light of the findings. Both agree that the thesis upon which Raynard Swank at the Graduate Library School, University of Chicago, expects to work will be the first study of fundamental importance. The second group disagrees on whether or not it is worth while studying other aspects of centralized technical processes before the fundamental work is done.

The local aspects of this disagreement are, of course, of no interest to librarians generally. It does seem, however, that the basic issue is of national importance. If a sufficient number of librarians interested in cataloging could concentrate their time and energy on basic studies in the nature of technical processes, it would not be long before we would be ready to take the next step: to decide on the basic structure to be used in meeting the bibliographic needs of college and university clientele. If, however, the time and energy of researchers is scattered on all aspects of the problem, it will be difficult to prevent getting the cart before the horse.

\section{Summary}

The following generalizations may be made in summary:

I. This group is discovering what other serious students of librarianship have learned, namely, that in spite of the large amount of literature about library centralization, specialization, or cooperation, there has been very little real research done on the basic elements of the problem, and that college librarians have frittered away their time and energy on minor aspects of the major problem without attacking the problem itself.

2. The group has learned that the large problems of university library specializa- tion, centralization, or cooperation are primarily curricular problems and only secondarily exclusive library problems, and that librarians alone are not, and never can be, in a position to solve the problems by themselves.

3. The group believes that more careful and systematic steps should be taken nationally and in various sections of the country to encourage meetings of university presidents, deans, members of the faculties, and librarians for the purpose of discussing the nature and implications of the problem of library specialization, centralization, and cooperation.

4. Some in our group think there is considerable danger in the present tendency of librarians to start programs of local, state, or regional cooperation or centralization (of technical processes) before all elements of the problem are thought through and all implications carefully considered.

5. Some in our group hope that the Library of Congress will not allow the reorganization of its technical processes to become fixed until it is certain that the present structure of cataloging is a sound one. Although a majority of college and university librarians may think it wise to accept and perfect the present cataloging structure, a substantial minority think it wise to do a little more research and creative thinking before a final decision is reached. The Library of Congress may be legally a Congressional library, but at the same time it has become a national instrument. It would be tragic indeed if it should interpret its responsibilities and opportunities too narrowly.

6. Since our group has been concerned up to this time primarily with the scope and direction programs of cooperation (Continued on page 244) 
or must be done in a great research library, have been sources of unending inspiration to all of us. And her assistance to me, as a new librarian coming into this great, complex institution, in helping me obtain the necessary background quickly and accurately for all the work to be done, is a debt that cannot readily be repaid.

\section{Diffusion of Knowledge}

As Dr. William S. Learned has pointed out :

The distinction between discovery and spread ... of ideas is clear, but it is often largely a matter of one's social philosophy or temperament as to which is considered to be of the greater importance. These two great processes of civilization are ... complementary, for accurate knowledge thoroughly diffused is, in the long run, the best possible preparation for fresh discovery. ${ }^{8}$

The careers of Miss Atwood, Miss Colcord, and Miss Lacy substantiate Dr. Learned's thesis that discovery and dissemination of knowledge must proceed together. The usefulness of their work to both the advancement and diffusion of knowledge is attested by scientists, administrators, and librarians alike. The bibliographical structures they have provided are the reference tools of today and the foundations upon which those whom they have trained may build the bibliographical tools of the future.

${ }^{8}$ Learned, William S. The American Public Library and the Diffusion of Knowledge. Harcourt, Brace, I 924 , p. 3.4.

\section{Activities of the Colorado Conference of Librarians of Institutions of Higher Learning}

(Continued from page 238)

might take, it is inevitable that we have been unable to turn our attention to smaller and less pretentious activities that would yield results of a more practical and useful nature. As yet we haven't done anything that has saved a single dollar.
But we agree that unless time can be found for both kinds of activities, for the time being at least we shall continue stirring up trouble and disturbing the status quo. That kind of thing seems to suit our collective predispositions very well. 